\title{
ANALYSIS OF NON-WORKING MOVES PERFORMED BY SEMI- MOUNTED REVERSIBLE PLOUGH IN A HEADLAND
}

\author{
Krasimir Trendafilov \\ Trakia University, Faculty of Techniques and Technologies \\ 38 Graf Ignatiev str., Yambol, Bulgaria, e-mail: krasimir@uni-sz.bg
}

\begin{abstract}
When working with semi-mounted reversible plough non-working moves are turns made at the end of the field when changing the direction of movement. The choice of a turn with the smallest length and duration of performance is hampered significantly when processing fields with irregular shape.

Three types of turns are compared in the article - oblong pear-shaped, shortened pear-shaped and eight-shaped when the angle between the direction of movement and the border of the field ranged from 20 to $90^{\circ}$. It is assumed that the angle is positive when it is on the right side of the unit when it enters into the turn, and negative - on the left side. The lengths of the curvilinear and the rectilinear part of the turn and the width of the headlands have been determined.

It was found that when the angle is positive the left turns have smaller length than the right turns, while when the angle is negative - vice versa. The shortened pear-shaped turns are the shortest followed by the oblong pear-shaped turns and the eight-shaped turns, but require greater headland than them. For small values of the angle the shortened and the oblong pear-shaped turns have similar lengths and widths of headlands.
\end{abstract}

Keywords: semi-mounted reversible plough; non-working move; field with irregular shape; pearshaped turn; eight-shaped turn; length of turn; width of headland.

\section{INTRODUCTION}

When plowing with reversible plough shuttle movement is made, i.e. the working moves are performed immediately next to each other. Nonworking moves are performed by the plough in headlands in the transition between the working moves. The turns can be with a different form. Most common in shuttle movement of trailed and semi-mounted units the regular pearshaped turn ( $\Omega$-turn) is used, but when the form of the field is not correct (other than rectangular) the shape of the turn is changing. In fields with irregular shape other types of turns can be used when plowing with semi-mounted reversible plough [1,2]. The length of the turns and the width of the headland depend on the form of the field. When the field is with irregular shape, the angle between the direction of movement of the unit and the border of the field has a major influence on these parameters.

Dependencies to determine the length of three types of turns and the width of the headland in ploughing in a field with irregular shapes are referred in $[1,2]$. They can be used to perform a comparative analysis of the different ways of movement and the study of the impact of the shape of the field on the length of the turn and width of the headland in ploughing with different units. The length of the turns has influence on the time for its performance, and it is the basis for the determination of effectiveness of the units. The width of the headland should be minimal. It is processed last and is associated with the additional expense of time.

The objective of this work is to make a comparative analysis of the non-working moves when ploughing with semi-mounted reversible plough and to determine the influence of the shape of the field on the length of the turn and the width of the headlands. 


\section{IRTITE}

Ipplied Reseirl'ches in Technics, Technologies and Bducation

Journal of the Faculty of Technics and Technologies, Trakia University https:///ites.google.com/a/trakia-uni.bg/artte/

\section{METODS}

To determine the length of the turns of the units and the width of the headland the dependencies specified in [1, 2] are used. They are processed and summarized in Table 1.

Table 1. Analytical dependences for determining the length of the turn and the width of headland when ploughing with semi-mounted reversible ploughs in a field with irregular shape.

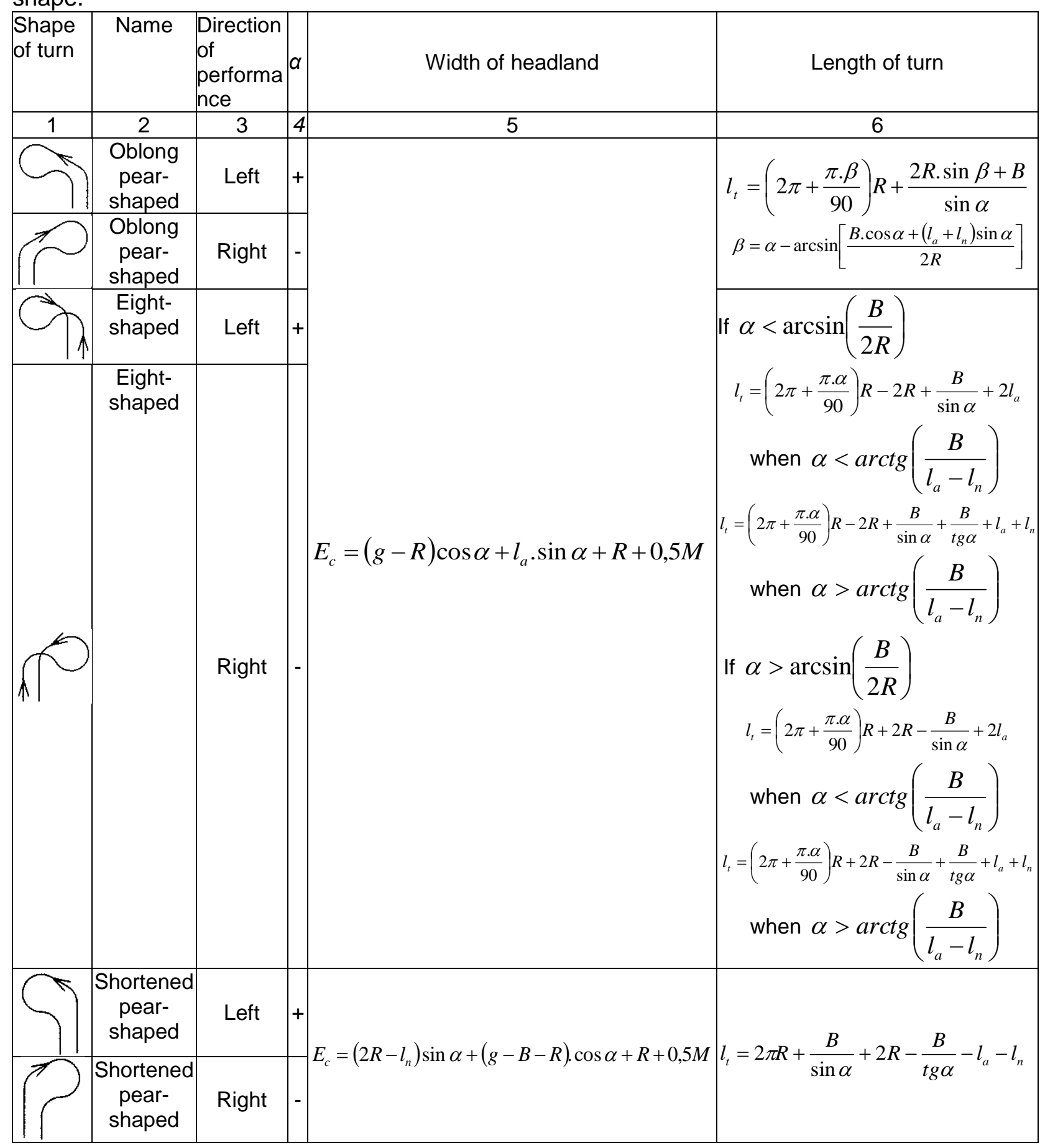

IRTITE Vol. 5, No. 2, 2017 ISSN 1314-8788 (print), ISSN 1314-8796 (online), doi: 10.15547/artte.2017.02.001 


\section{IRTITE}

Ipplied Researloches in Technics, Technologies and Bductition Journal of the Faculty of Technics and Technologies, Trakia University https://sites.google.com/a/trakia-uni.bg/artte/

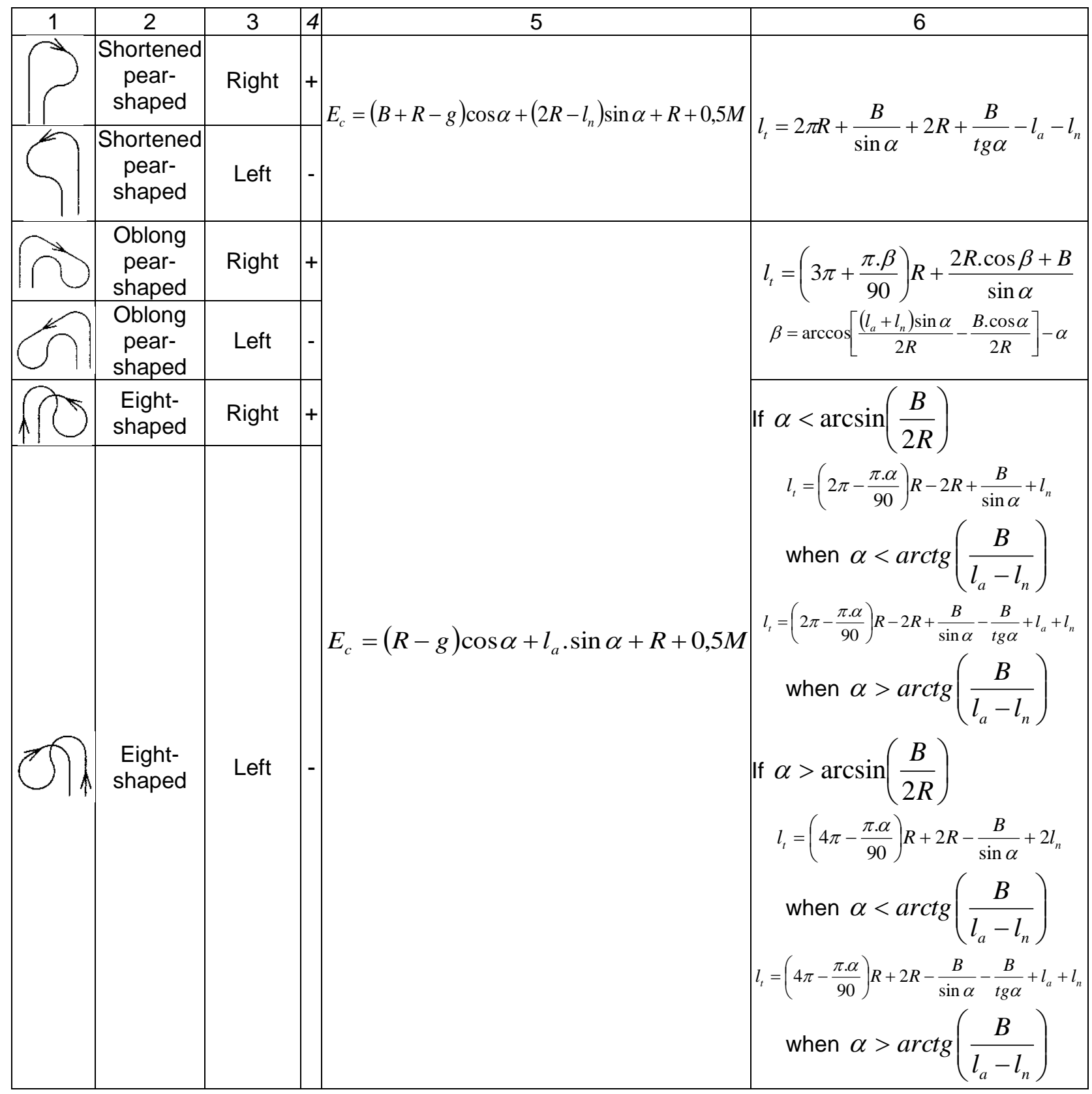

In [1] the length of the turn is calculated from the point of include or exclude of the machine inside the headland by not take into consideration rectilinear area which the unit covers between this point and the border of the headland. When system for precision agriculture is used, inclusion and exclusion of the unit can be performed exactly on the border of headland. In the dependencies listed in Table 1, the length of the turn is the distance covered by the unit from exclusion the machine when the last ploughshare reaches the border of the headland to the its inclusion for the next move when the first ploughshare again reaches on the border of the headland. In the dependencies for the calculation of the length of the turns $\left(I_{t}\right)$ the first member represents the length of the curvilinear part of the turn $\left(I_{c}\right)$, the rest addends form the length of the rectilinear part of the turn $\left(I_{r}\right)$. Three types of turns are discussed - oblong pear-shaped, shortened pear-shaped and eight-shaped. The symbols in Table 1 have the following meanings:

IRTITE Vol. 5, No. 2, 2017 ISSN 1314-8788 (print), ISSN 1314-8796 (online), doi: 10.15547/artte.2017.02.001 


\section{ART'TE $Y$}

Ipplied Resseirlohes in Technics, Technologies and Bductation

Journal of the Faculty of Technics and Technologies, Trakia University https://sites.google.com/a/trakia-uni.bg/artte/

$E_{c}$ - the required minimum width of headland;

$I_{t}-$ the length of the turn;

$\alpha$ - the angle between the direction of movement of the unit and the border of the field. It is assumed that the angle is positive when it is on the right side of the unit when it enters into the turn, and negative - on the left side (Figure 1). For this study is accepted that the angle is positive and it is in the range of $20^{\circ}$ to $90^{\circ}$. In the calculations the angle is always with positive sign. When the angle is negative same dependencies are valid, but the names of turns are changed according to Table 1, and the direction of making the turns must be reversed;

$\beta$ - angle from geometric construction of the turn required for the calculation of the length of the individual parts of the turn. It depends on the angle $\alpha$;

$B$ - the working width of the unit;

$I_{a}-$ the kinematic length of the unit;

$I_{n}$ - the distance from the center of the unit (the middle of the rear axle of the tractor) to at front point of the first ploughshare;

$g$ - the distance from the axis of symmetry of the tractor to at front point of the last ploughshare;

$R$ - the radius of the turn of the unit;

$M$ - the distance between the outer boards of the rear tires of the tractor.

The actual width of the headland $E$ must be exact multiples of the working width of the unit

$$
E=k . B,
$$

where $\mathrm{k}$ is the number of moves of the unit for processing of headland.

The number of moves for the processing of headland will depend on angle $\alpha$. In equalizing dependence (1) with dependencies Ec in Table 1 is determined the number of the moves $k$ and the value of angle $\alpha$, where the width of the headland is changed. The result obtained for $\mathrm{k}$ is rounded up to the higher whole number and is replaced in (1).

On the basis of the dependencies graphics have built for the influence of angle $\alpha$ on the width of the headland and the length of the turns. The calculations are made for the unit with the following parameters: $B=2,4 \mathrm{~m} ; l_{a}=6,5 \mathrm{~m} ; g=1,75 \mathrm{~m} ; l_{n}=2 \mathrm{~m} ; R=7,2 \mathrm{~m} ; M=2,1 \mathrm{~m}$.

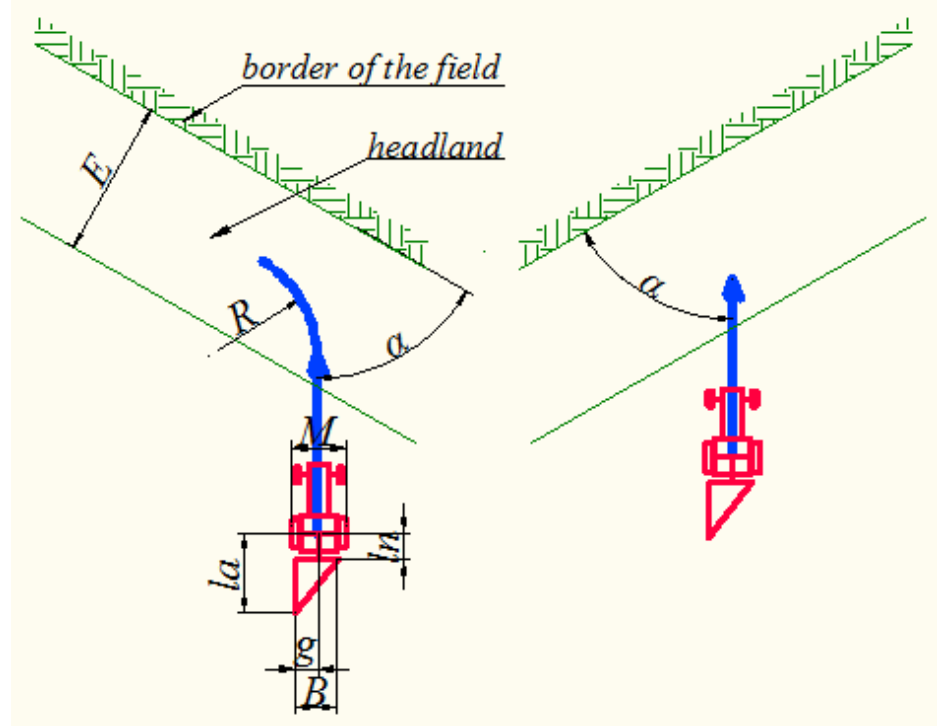

Figure 1. Movement of the unit in a field with irregular shape:

a) in a positive angle between the direction of movement of the unit and the border of the field

b) in a negative angle between the direction of movement of the unit and the border of the field 


\section{IRTITIE}

Ipplied Researrches in Technics, Technologies and Educiation Journal of the Faculty of Technics and Technologies, Trakia University https://sites.google.com/a/trakia-uni.bg/artte/

\section{RESULTS}

In Figure 2 the results of the calculations of the length of the turns and the width of the headland are shown. It can be seen that with increasing angle $\alpha$, the length of the oblong pear-shaped turn (Figure 2a) increases, as the length of the curvilinear part of the turn grows faster. The width of the headland also grows. If the turn is on the right (Figure $2 b$ ) its length decreases with increasing $\alpha$, which is also due to the more rapid change of the curvilinear part of the turn. In this case, the width of the headland remains constant regardless of the form of the field. The length of the right turn is greater than the length of the left turn, but when $\alpha=90^{\circ}$, i.e. at the correct form of the field, the lengths of the turns are equal. The widths of the headlands are also equal.

In Figure 2c and Figure 2d are shown graphs for shortened pear-shaped left and right turns. It is seen that the length of the left turn is less than the length of the right turn as they are equal at $\alpha=90^{\circ}$. With the increasing of the angle $\alpha$, the length of the curvilinear part of the turn does not change regardless of the direction of performance. The length of the rectilinear
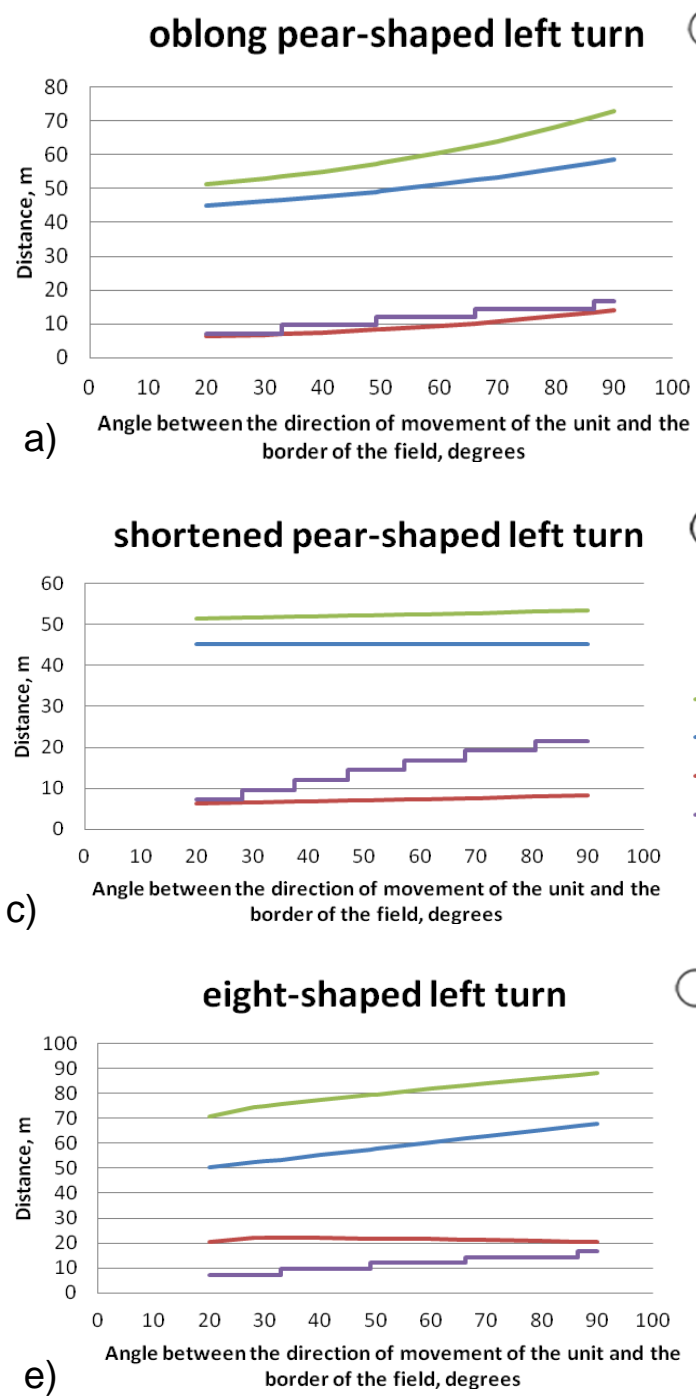
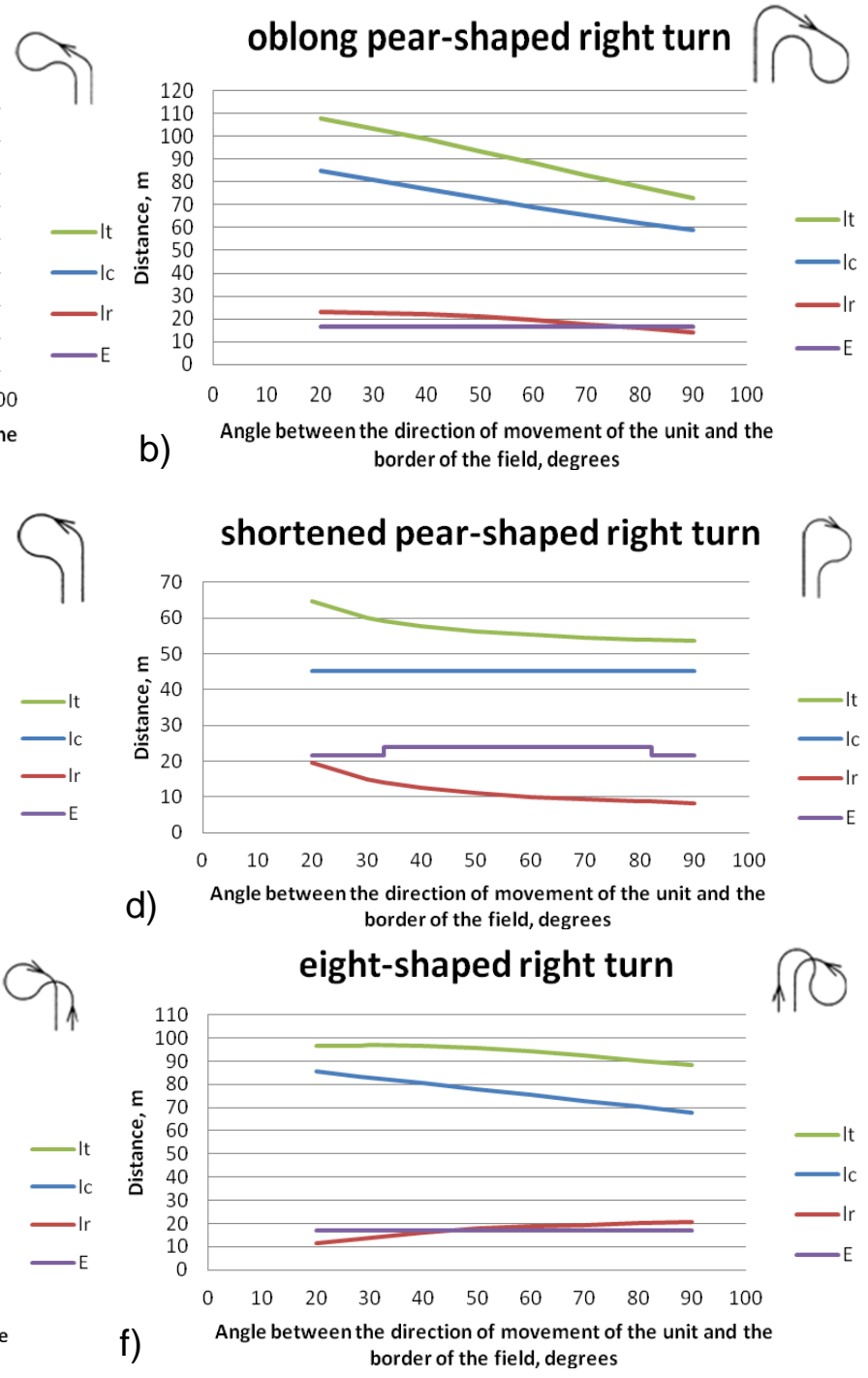

Figure 2. Length of the turns and width of the headland

IRTIIE Vol. 5, No. 2, 2017 ISSN 1314-8788 (print), ISSN 1314-8796 (online), doi: 10.15547/artte.2017.02.001 


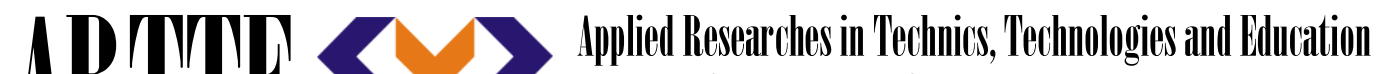 Journal of the Faculty of Technics and Technologies, Trakia University https://sites.google.com/a/trakia-uni.bg/artte/}

part of the turn increases significantly at the left turn and decreases faster at the right turn. The width of the headland is smaller in the left turn and increases with increasing the angle $\alpha$ and in the great value of the angle is equal to the width of the headland in the right turn.

In Figure $2 \mathrm{e}$ and Figure $2 f$ the results for eight-shaped turns are shown. They have the same character of change of the total length of the turn and the width of the headland as the other turns. The difference compared to the other turns is the change in the length of the rectilinear part of the turn. In the eight-shaped left turn with increasing the angle $\alpha$, the length of the rectilinear part of the turn initially increases slightly until the boundary condition $\alpha=\operatorname{arctg}\left(\frac{B}{l_{a}-l_{n}}\right)$, then decreases, while on the remaining left turns the length of the rectilinear part is increases. In the eight-shaped right turn the length of the rectilinear part increases, while in the other right turns decreases.

From the results it can be seen that the eight-shaped turns are with the greatest length. They are followed by the oblong pear-shaped turns. The shortened pear-shaped turns are with the smallest length. The width of the headland is the same for the eight-shaped turns and the oblong pear-shaped turns. It is smaller than the width of the headland of the shortened pearshaped turns. The left turns have less length and narrower headland in comparison with the right turns. For small values of angle $\alpha$, the oblong pear-shaped turns and the shortened pear-shaped turns have equal lengths and widths of headlands.

\section{CONCLUSIONS}

- When the angle between the direction of movement and the border of the field is positive the left turns are shorter than the right turns, when the angle is negative - vice versa.

- The shortened pear-shaped turns have the shortest length, followed by the oblong pearshaped turns and the eight-shaped turns, but require wider headland than them.

- For small values of the angle the shortened pear-shaped turns and the oblong pearshaped turns have similar lengths and widths of the headlands.

\section{REFERENCES}

[1] Trendafilov K. (2011). Theoretical determination of the length of turn when ploughing with a trailed and semi-mounted reversible ploughs in a field with irregular shape. Agricultural engineering, 2011, № 3, 23-29.

[2] Trendafilov K. (2010). Theoretical determination of the width of strip for turning when ploughing with trailed and semi-mounted reversible ploughs in a field with irregular shape, Agricultural science and technology, Volume 2, Number 4, December 2010. 